\title{
Thermally Activated Concrete Slabs with Integrated PCM Materials
}

\author{
Renars Millers ${ }^{1, *}$, Aleksandrs Korjakins ${ }^{2}$, and Arturs Lesinskis ${ }^{1}$ \\ ${ }^{1}$ Institute of Heat, Gas and Water Technology, Riga Technical University, Kalku street 1, Riga, LV-1658, Latvia \\ ${ }^{2}$ Institute of Materials and Structures, Riga Technical University, Kalku street 1, Riga, LV-1658, Latvia
}

\begin{abstract}
As building codes are pushing towards higher energy efficiency and the arrival of nearly Zero Energy Building (nZEB) requirements for all new buildings are just around the corner the need for alternative, high efficiency heating and cooling solutions for nZEB's is greater than ever. Also as experience with renewable energy sources has proven the energy demand and energy generation rarely overlaps and it does not allow to fully utilise some renewable energy sources. This is a simulation study that focuses on integrated cooling and energy storage system utilising phase-change materials (PCM). Several types of thermally activated slabs with different PCM thicknesses were simulated in order to find the most optimal PCM thickness with melting point temperature that can support passive cooling methods based on adiabatic cooling principles. Two calculation tools were used for the study - IDA ICE 4.8 and U-NORM 2012-2 to calculate the properties of the slabs and potential of application in well insulated residential building in Baltic climate. The results showed that the optimal thickness for thermally activated PCM layer (large flat containers) range from $25 \mathrm{~mm}$ to $90 \mathrm{~mm}$, and for layers with no thermal activation - $180 \mathrm{~mm}$ and more. Moreover the results show that apart from energy storage the thermally activated panel can increase thermal comfort conditions.
\end{abstract}

\section{Introduction}

Nowadays cooling systems are becoming more widespread in residential building sector in Central European as well as Northern European climate [1]. Currently Cooling equipment is responsible for approximately $20 \%$ of total building energy consumption worldwide. The installed cooling capacity in the world has tripled since 1990 and the energy consumed by cooling equipment will triple by 2050 . The highest cooling capacity growth has been in the residential sector [2]. This phenomenon can be explained by increased demand for thermal comfort due to increased standard of living in most parts of the world [2]. Another factor that might increase the installed cooling capacity in the future is highly insulated and air-tight buildings and climate change [3]. It has been reported that retrofitted and newly constructed highly insulated buildings experience more overheating even in Nordic countries due to internal and external heat gains [4]. The overheating can occur in sunny days almost independent of outdoor air temperature. Thermally activated building constructions such as slabs with integrated phase-change materials (PCM) can help to solve this problem in a smart way by offsetting the heat build-up in rooms preferably by accumulating the energy to use it later or extract it from the building by passive means. The same thermally activated slab system can be used to support passive heating systems or store thermal energy in order to utilise lower electricity rates during night time or photovoltaics (PV) production peaks.

Numerous studies have reported the effectiveness for implementing PCMs in different structures. The reported effectiveness of implementing PCM's in different structures range from $1{ }^{\circ} \mathrm{C}$ to $4^{\circ} \mathrm{C}$ of maximum temperature reduction $[5,6,7,8]$. However most of the studies focus on micro-capsulated and macro-capsulated PCM with no thermal activation. Also many of the studies have reported problems with solidification of PCM layers after hot periods [9, 5, 10].

The optimal melting temperatures for PCMs integrated in building constructions are reported to be in a range from $21^{\circ} \mathrm{C}$ to $26^{\circ} \mathrm{C}$ for passive systems $[7,11$, $12]$.

This study focuses on investigating options of using thermally activated precast concrete slabs with integrated PCMs (precast-concrete panel sized flat container) for increasing thermal comfort and energy efficiency in well insulated residential buildings in Baltic climate. The scope of the study is the implementation of PCM rather than the materials itself thus no specific PCM was chosen for this study.

The main purpose of the study is to use PCM to support passive cooling techniques like free cooling and adiabatic cooling.

Corresponding author: renars.millers@gmail.com 
This study focused on following objectives:

- To investigate the application of a PCM with $\sim 23^{\circ} \mathrm{C}$ phase change temperature that can support high temperature passive cooling based on adiabatic cooling principles.

- To find the optimal thickness of PCM layer to even out the swings in internal and external heat gains;

- To model the temperature and heat flow distribution in the thermally activated concrete panel;

\section{Methodology}

\subsection{Software}

IDA ICE 4.8 was used for modelling energy balance and its interaction with the thermally activated building constructions and mechanical systems. U-NORM 2012 was used to model the temperature distribution and heat flow in the thermally activated slabs in order to calibrate the simulation model.

\subsection{The simulation model}

A generic single zone simulation model was used to generate multiple simulation cases with different slab options and facade orientations. Visual representation of the simulation model is shown in Figure 1. The generalised simulation input data is illustrated in Table 1.

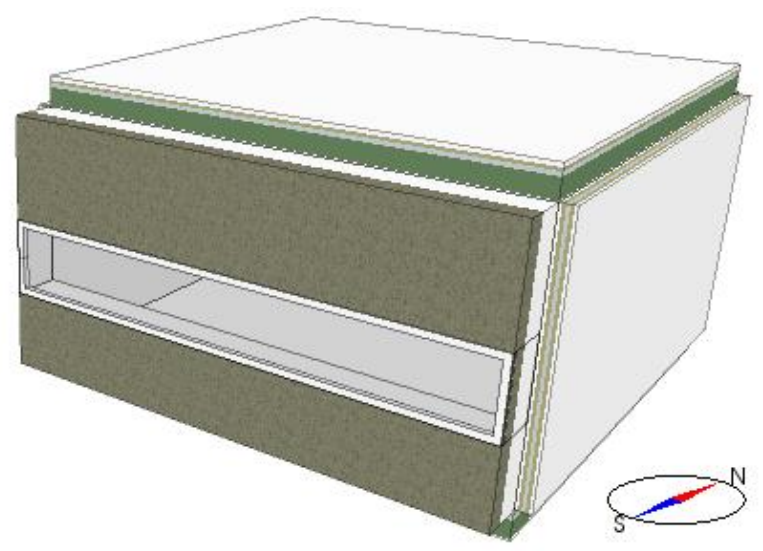

Fig. 1. Single zone model used for the study

Table 1. Simulation input data

\begin{tabular}{|c|c|}
\hline Location & 56.97 N 24.07 E (Riga, Latvia) \\
\hline $\begin{array}{c}\text { Zone } \\
\text { dimensions }\end{array}$ & $5.0 \times 5.0 \times 2.6 \mathrm{~m}(\mathrm{LxWxH})$ \\
\hline Floor area & $25 \mathrm{~m}^{2}$ \\
\hline Orientation & $\mathrm{N}, \mathrm{S}, \mathrm{W}, \mathrm{E}$ (4 orientation scenarios) \\
\hline $\begin{array}{c}\text { U value of } \\
\text { external } \\
\text { walls }\end{array}$ & $0.13 \mathrm{~W} / \mathrm{m}^{2} \cdot \mathrm{K}$ \\
\hline Glazing & $30 \%$ of facade area \\
\hline $\begin{array}{l}\mathrm{U} \text { value for } \\
\text { glazing }\end{array}$ & $1.0 \mathrm{~W} / \mathrm{m}^{2} \cdot \mathrm{K}$ \\
\hline
\end{tabular}

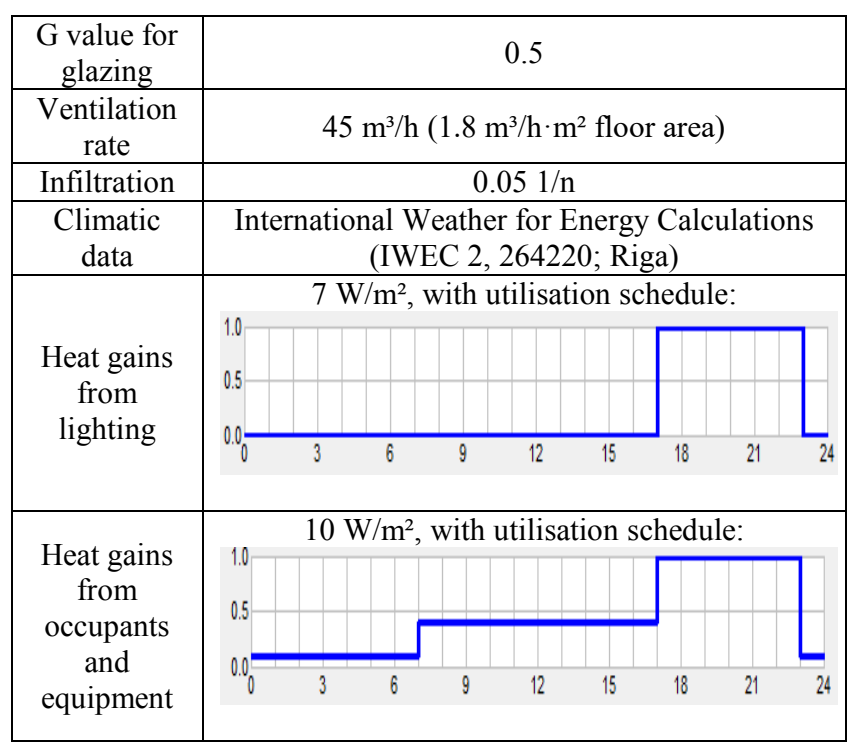

\subsection{The modelled slab scenarios}

For each orientation scenario different sub-scenarios were generated containing different slab options with and without thermal activation as well as with and without PCM layers of thicknesses varying from $15 \mathrm{~mm}$ to $180 \mathrm{~mm}$. It was assumed that the PCM would be filled in a container with integrated hydronic circuit. See Table 2 for different slab options.

The applied PCM has following physical properties: melting and solidifying point of $23^{\circ} \mathrm{C}$ and phase change enthalpy of $130 \mathrm{~kJ} / \mathrm{kg}$ (Density 1350 $\mathrm{kg} / \mathrm{m}^{3}$ ). Similar physical properties may correspond to several new and cycled organic PCMs, for instance, Rubitherm RT22HC [13].

The phase change temperature of $23^{\circ} \mathrm{C}$ was chosen as it is sufficient to support cooling circuit temperature achievable from adiabatic cooling equipment in Baltic sea region (see section 2.3 Cooling plant).

Table 2. Sub-scenarios of different slab options

\begin{tabular}{c} 
P0T0 \\
Base case - regular panel without PCM and thermal activation \\
(Layers starting from top: $40 \mathrm{~mm}$ screed, $30 \mathrm{~mm}$ insulation, \\
precast concrete panel, $180 \mathrm{~mm}$ air gap, gypsum board $13 \mathrm{~mm})$ \\
\hline Pame as P0T0 but with integrated cooling circuit sized for \\
\hline $100 \mathrm{~W} / \mathrm{m}^{2}$ \\
\hline precast concrete panel, $180 \mathrm{~mm}$ PCM container, gypsum board \\
$13 \mathrm{~mm}$ (1) \\
\hline
\end{tabular}




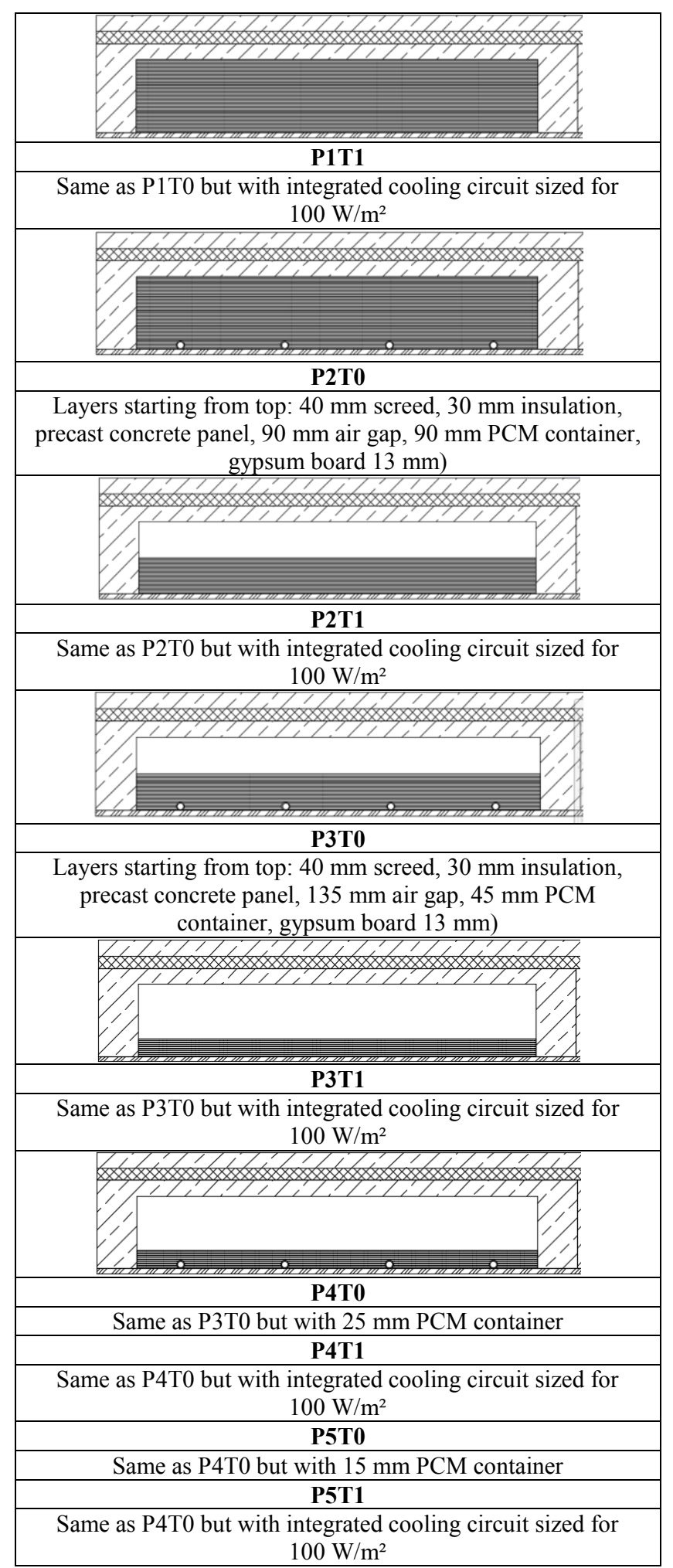

\subsection{Thermal properties of the slabs}

Thermal modelling in U-NORM was used to determine heat transfer coefficients for cooling circuits according to EN 15377-1 [14]. The modelled heat transfer coefficient is $0.32 \mathrm{~W} / \mathrm{m}^{2} \mathrm{~K}$ for the upward direction and $4.1 \mathrm{~W} / \mathrm{m}^{2} \mathrm{~K}$ for the downward direction in the P1T1 case, for visual representation see Figure 2.
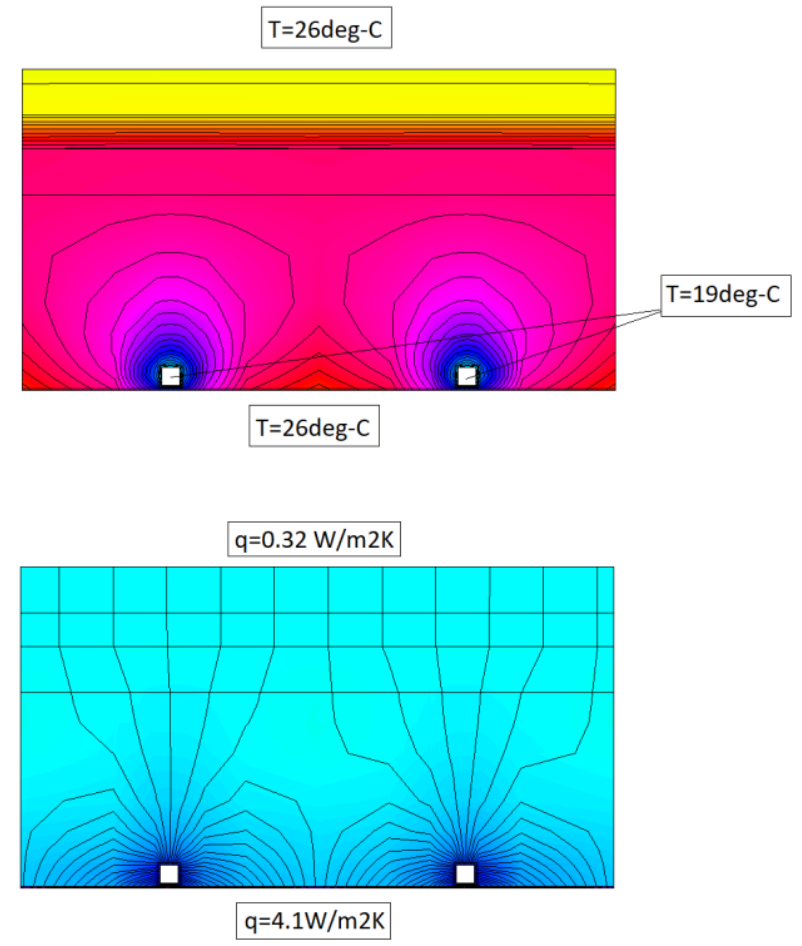

Fig. 2. Visual representation of temperature (upper image) and specific heat flow (lower image) distribution for the P1T1 panel case.

\subsection{Cooling plant}

Since outdoor air wet bulb temperature in Northern Europe rarely exceed $20^{\circ} \mathrm{C}$ (see Table 3) adiabatic freecooling systems have high potential when combined with high temperature cooling and PCM heat storage. A cooling plant with only adiabatic cooling system is selected for this study in order to report results that can be achieved with purely passive means of cooling.

Table 3. 1\% Annual exceedance of outdoor air wet bulb temperature in different Baltic Sea region cities [15]

\begin{tabular}{|c|c|}
\hline City & $\begin{array}{c}\text { Wet bulb (WB) temperature } \\
\text { corresponding } 1 \%(87.6 \mathrm{~h}) \\
\text { annual exceedance }\end{array}$ \\
\hline Riga & $20.4^{\circ} \mathrm{C}$ \\
\hline Tallinn & $19.0^{\circ} \mathrm{C}$ \\
\hline Helsinki & $19.4^{\circ} \mathrm{C}$ \\
\hline Stockholm & $18.8^{\circ} \mathrm{C}$ \\
\hline
\end{tabular}

\section{Results}

\subsection{Cooling circuit}

Simulation with IDA ICE 4.8 was performed on 48 cases containing different zone orientation and slab composition.

The results show that adiabatic cooling can deliver $19^{\circ} \mathrm{C}$ supply temperature in the cooling circuit for 8449 hours a year and only 311 hours of mechanical cooling is required. See Figure 3. 


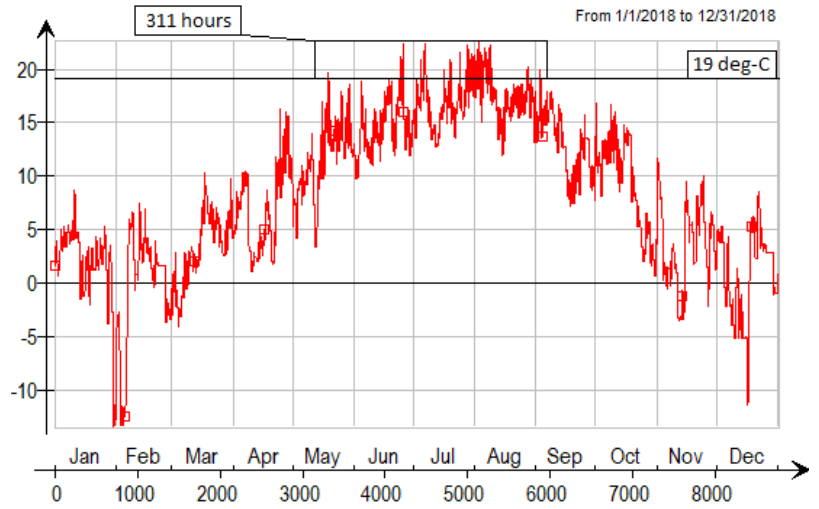

Fig. 3. Available cooling circuit supply temperature from adiabatic cooling equipment (assumed that the achievable supply temperature is $2^{\circ} \mathrm{C}$ higher than the outdoor air WB temperature)

\subsection{PCM layer thickness}

Results show that building with no PCMs and no cooling circuits are the most likely to overheat (see Figure 4). The presence of PCM layer with no cooling circuit gives just a slight improvement of approximately $2^{\circ} \mathrm{C}$ (which is consistent with other studies [7,8]) lower maximal temperature because most part of the year the PCM is in a liquid state with no potential to reject thermal energy and solidify (see figure 6). Similar problems have been reported in other studies $[5,9,10]$. All scenarios without a cooling circuit regardless of the thickness of the PCM resulted in 2600-5900 annual hours exceeding $27^{\circ} \mathrm{C}$ operative temperature. This cannot be considered comfortable indoor climate.

Introduction of a cooling circuit gives a beneficial improvement. West oriented zones with a cooling circuit and no integrated PCMs performed better by achieving $\sim 29^{\circ} \mathrm{C}$ maximum indoor operative temperature than North oriented zones with $180 \mathrm{~mm}$ PCM layer and no cooling circuit where maximum operative temperature reached $\sim 33^{\circ} \mathrm{C}$. For North oriented zones operative temperature below $27^{\circ} \mathrm{C}$ could be reached all year round.

The best performing scenarios were the ones with both a PCM layer and a cooling circuit with maximum operative temperatures that were reached in a whole year simulation ranged from $25.5^{\circ} \mathrm{C}$ to $28.3^{\circ} \mathrm{C}$. Figure 5 shows number of hours per year when the operative temperature exceeds $27^{\circ} \mathrm{C}$ (category III threshold according to EN 15251 [16]) for different PCM thicknesses with a cooling circuit present. With a PCM thickness of $45 \mathrm{~mm}$ and a cooling circuit indoor operative temperatures of $27^{\circ} \mathrm{C}$ can be reached all year round for all orientations except the West where the exceedance is $\sim 19$ hours a year.

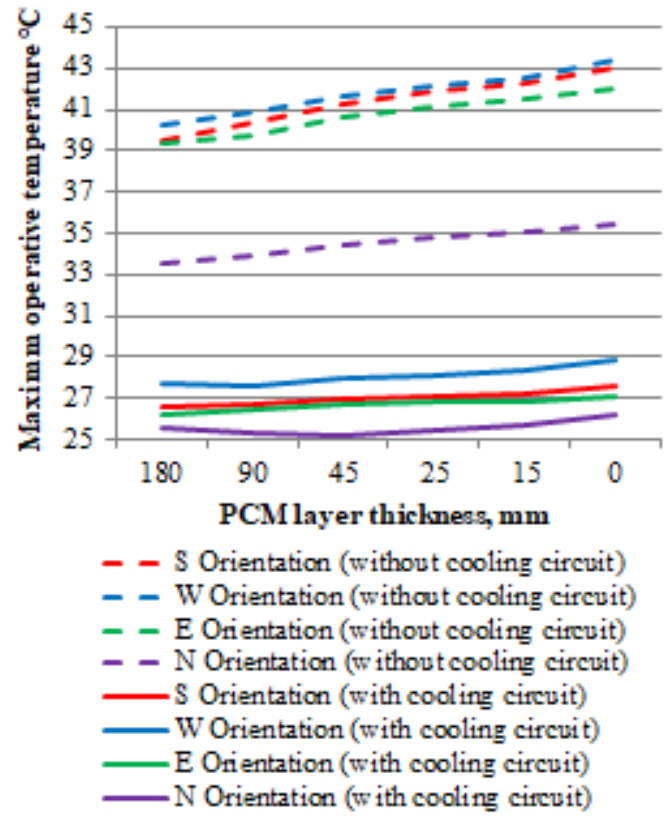

Fig. 4. Maximum operative temperature reached during a full year simulation.

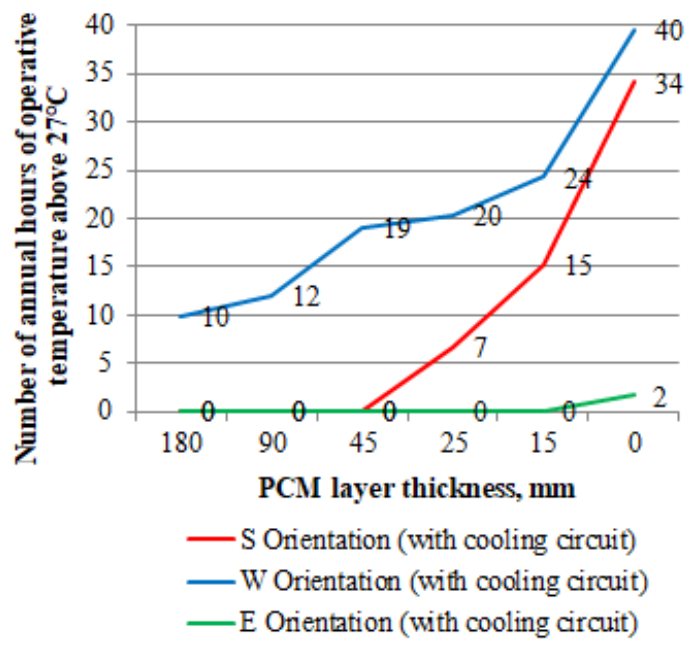

Fig. 5. Number of hours per year with operative temperature exceeding $27^{\circ} \mathrm{C}$

In cases with no cooling circuit the PCM is in liquid state for more than 5000 hours a year. The number of hours during which the phase change (and also energy transfer) takes place in the PCM increases by increasing the thickness of the PCM. This can also be observed in Figure 6.

It can be concluded that if the PCM layer is not thermally activated the efficiency of the system is more dependent on the thickness of the PCM. Also the Phase change takes place only during autumn and spring season making the PCM useless in the summer season (see Figure 8).

From Figure 7 it can be observed that the periods of phase change are greatly increased if a cooling circuit is present. Also they are less dependent on the thickness off the PCM layer. In Figure 7 and 8 it can be observed that most part of the year the PCM is in solid state and 
the phase change mostly takes place in the summer season. Around 260 hours a year the PCM is in liquid state due to high outdoor wet bulb temperatures (see also Figure 3). If the PCM layer thickness is increased to $180 \mathrm{~mm}$ the liquid state can be avoided at all.

For slabs with PCM layers but no thermal activation the optimal thickness is not between $15 \mathrm{~mm}$ and $180 \mathrm{~mm}$ because the process efficiency keeps increasing even after the $180 \mathrm{~mm}$ thickness.

The optimal PCM thickness for thermally activated slabs could range from $25 \mathrm{~mm}$ to $90 \mathrm{~mm}$ depending on orientation. PCM thicknesses beyond $90 \mathrm{~mm}$ give relatively small improvement considering a significant increase of thickness. For a South facing zone and thermally activated panel the scenario of $25 \mathrm{~mm}$ PCM thickness proved to be sufficient to achieve 8760 hours a year of III Comfort category and 6821 hours of I Comfort category according to EN-15251 [16] (see Figure 9).

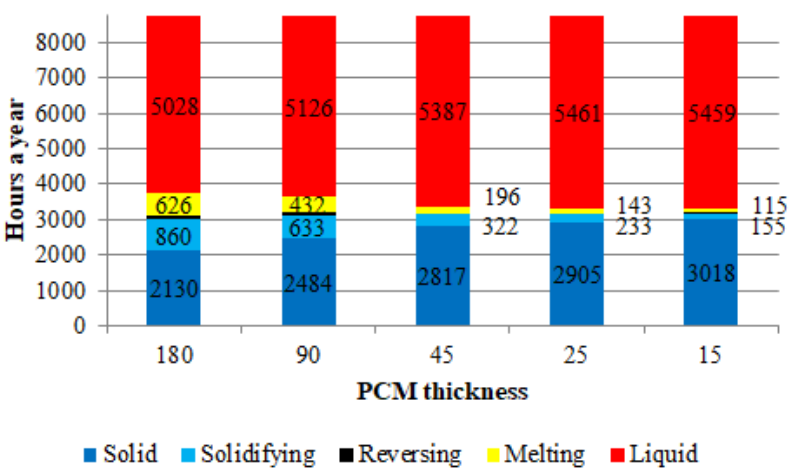

Fig. 6. PCM State for South facing zones without a cooling circuit

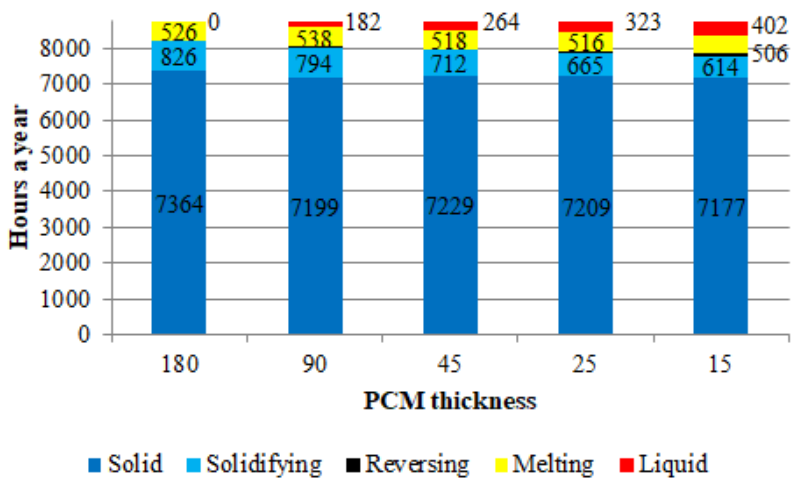

Fig. 7. PCM State for South facing zones with a cooling circuit

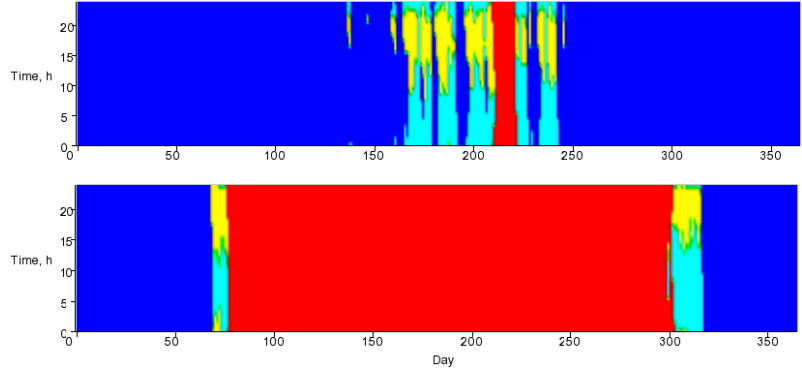

Fig. 8. Carpet plot of PCM state in South facing zone with $45 \mathrm{~mm}$ PCM layer with a cooling circuit (upper image) and without a cooling circuit (lower image). States: red - liquid, yellow - melting, light, green - reversing, light blue solidifying, dark blue - solid.

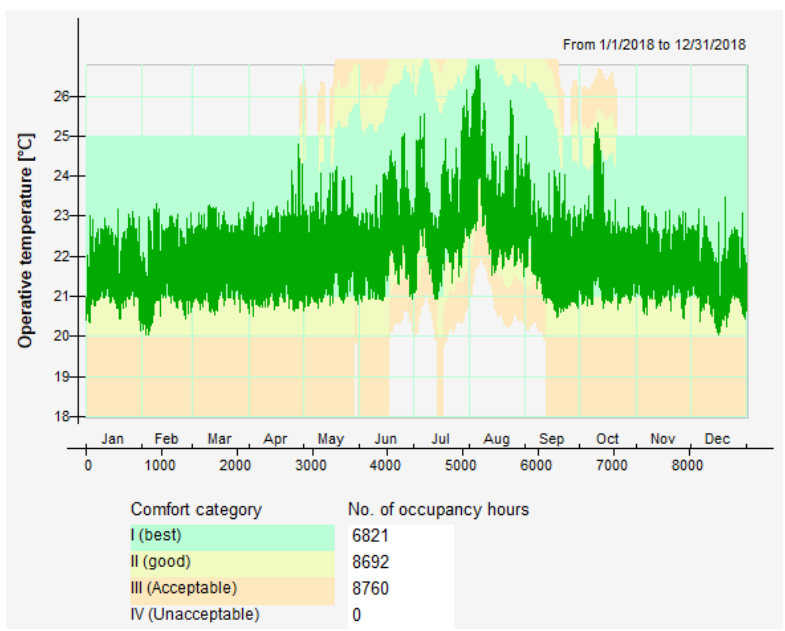

Fig. 9. Occupancy hour distribution according to comfort category (EN 15251 [16]). For South facing P2T1 panel case.

\section{Conclusion}

After the research work done it can be concluded that based on the climatic data (especially the annual WB temperatures) of different cities of the Baltic region a $23^{\circ} \mathrm{C}$ PCM melting point is suitable for use in systems that utilise adiabatic cooling principles for high temperature cooling and regenerating PCM layers that are enclosed in building structures. This PCM melting point temperature is consistent with temperatures reported in other studies [11]. In a typical climate in Riga (Latvia) and adiabatic cooling system would be able to reach supply temperature below $19^{\circ} \mathrm{C}$ for around 8450 hours a year leaving only a period of around 300 hours where the supply water temperature cannot be met with passive means.

The optimal PCM layer thickness can vary depending on the orientation that the zone is facing and more importantly whether the PCM layer is thermally activated. Optimal PCM thickness for thermally activated layers is between $25 \mathrm{~mm}$ and $90 \mathrm{~mm}$, a $180 \mathrm{~mm}$ layer gives a slightly better performance but with an expense of doubled thickness which would be impractical for most applications. Optimal thickness of PCM layers with no thermal activation is $180 \mathrm{~mm}$ and 
the efficiency increases resulting in impractical PCM layer thicknesses.

The modelled heat flow in a thermally activated slab with $\mathrm{PCM}$ container was $\sim 4.4 \mathrm{~W} / \mathrm{m}^{2} \cdot \mathrm{K}$ that gives $26 \mathrm{~W} / \mathrm{m}^{2}$ cooling power for a $6 \mathrm{~K}$ average room-water temperature difference, but the cooling circuit should be sized for a higher capacity to properly regenerate the PCM.

The financial support of the European Regional Development Fund project Nr.1.1.1.1/16/A/007 "A New Concept for Sustainable and Nearly Zero-Energy Buildings" is acknowledged.

\section{References}

1. A. Dengel, M. Swainson, D. Ormandy, V. Ezratty, Guidance document: Overheating in dwellings, Watford, Building Research Establishment (2016)

2. International Energy Agency, The future of Cooling (2018)

3. M. Auzeby, S. Wei, C. Underwood, C.Chen, H. Ling, S. Pan, B. Ng, J. Tindall, R. Buswell, Using phase change materials to reduce overheating issues in UK residential buildings, Energy Procedia, 105, 4072-4077 (2017)

4. B. Aebischer, G. Henderson, M. Jakub, G. Catenzzi, Impact of climate change on thermal comfort, heating and cooling energy demand in Europe, ECEEE 2007 Summer Study, Saving Energy JUST DO IT!, 859-870, (2007)

5. C. Voelker, O. Kornadt, M. Ostry, Temperature reduction due to the application of phase change materials, Energy and Buildings, 40, 937-944, (2008)

6. X. Shi, S.A. Memon, W. Tang, H. Cui, F. Xing, Experimental assessment of position of macro encapsulated phase change material in concrete walls on indoor temperatures and humidity levels, Energy and Buildings, 71, 80-87, (2014)

7. G. Zhou, Y. Yang, X. Wang, S. Zhou, Numerical analysis of effect of shape-stabilized phase change material plates in a building combined with night ventilation, Applied Energy, 86, 52-59, (2009)

8. A. Castell, I. Martorell, M. Medrano, G. Pérez, L.F. Cabeza, Experimental study of using PCM in brick constructive solitions for passive cooling, Energy and Buildings, 42, 534-540, (2010)

9. P. Arce, C. Castellón, A. Castell, L.F. Cabeza, Use of microencapsulated PCM in buildings and the effect of adding awnings, Energy and Buildings, 44, 88-93, (2012)
10. G. Evola, L. Marletta, F. Sicurella, A methodology for investigating the effectiveness of PCM wallboards for summer thermal comfort in buildings, Building and Environment, 59, 517-527, (2013)

11. Y. Han, J.E. Taylor, Simulating the Inter-Building Effect on energy consumption from embedding phase change materials in building envelopes, Sustainable Cities and Society, 27, 287-295, (2016)

12. S.M. Sajjadian, J. Lewis, S. Sharples, The potential of phase change materials to reduce domestic cooling energy loads for current and future UK climates, Energy and Buildings, 93, 83-89, (2015)

13. L. Navarro, A. Sole, M. Martin, C. Berreneche, L. Olivieri, J.A. Tenorio, L.F. Cabeza, Benchmarking of useful phase change materials for a building application, Energy and Buildings, 182, 45-50, (2019)

14. European Committee for Standardization, $E N$ 15377-1 Heating systems in buildings - Design of embedded water based surface heating and cooling systems - Part 1: Determination of the design heating and cooling capacity

15. ASHRAE, 2017 ASHRAE Handbook Fundamental, (2017)

16. European Committee for Standardization, EN 15251 Indoor environmental input parameters for design and assessment of energy performance of buildings addressing indoor air quality, thermal environment, lighting and acoustics 